\title{
Acessibilidade no campus universitário brasileiro: um estudo de caso do campus do Pici/Universidade Federal do Ceará
}

\author{
Accessibility in the brazilian university campus: a case study of the \\ Pici campus / Federal University of Ceará
}

\author{
PLÍNIO RENAN GONÇALVES DA SILVEIRA \\ Doutorando, PPGAU/Universidade Federal do Rio Grande do Norte, pliniorenan@gmail.com
}

ZILSA MARIA PINTO SANTIAGO

Doutora, PPGAUD/Universidade Federal do Ceará, zilsa@arquitetura.ufc.br

\section{RESUMO}

Um novo cenário, no que tange à inclusão, se apresenta com a sanção da Lei no 13.409 de 28 de dezembro de 2016 que estabelece reservas de vagas para pessoas com deficiência nos cursos de nível superior das instituições federais, repercutindo em um considerável aumento destas matrículas. Neste contexto, a presente pesquisa questiona se os espaços destas instituições estariam preparados para receber estes estudantes. A pesquisa se insere na temática da acessibilidade espacial em espaços universitários, tendo como estudo de caso o campus universitário do Pici na UFC, situado em Fortaleza, com objetivo de avaliar a infraestrutura e seus rebatimentos no acolhimento de estudantes com deficiência. A pesquisa de campo fundamenta-se em metodologias empíricas e qualitativas sob três diferentes perspectivas: "Walktrough exploratória" (RHEINGANTZ et al, 2009) por meio da observação do campus, "Avaliação técnico-funcional" (ORNSTEIN, ROMERO 1992) com base nos parâmetros estabelecidos na NBR9050/2015, NBR16537/2016, Decreto 5.296/2004, entre outros, e por fim, "Passeio acompanhado" (DISCHINGER, 2000) a partir da percepção de estudantes com deficiência. Os resultados apresentam a atual conjuntura de uma IFES diante dos desafios para garantir o acesso destes estudantes e algumas recomendações para reforma e construção de campi acessíveis.

PALAVRAS-CHAVE: Acessibilidade; Espaços universitários; Universidade Federal do Ceará; Lei de cotas

\section{ABSTRACT}

A new scenario, with regard to inclusion, presents itself with the sanction of Law No. 13.409 of December 28, 2016, which establish reserve openings for persons with disabilities in higher education courses of federal institutions, resulting in a considerable increase in these enrollments. In this context, the present research questions if the spaces of these institutions would be prepared for the reception of these students. The study is part of the theme of spatial accessibility in university spaces, having as 


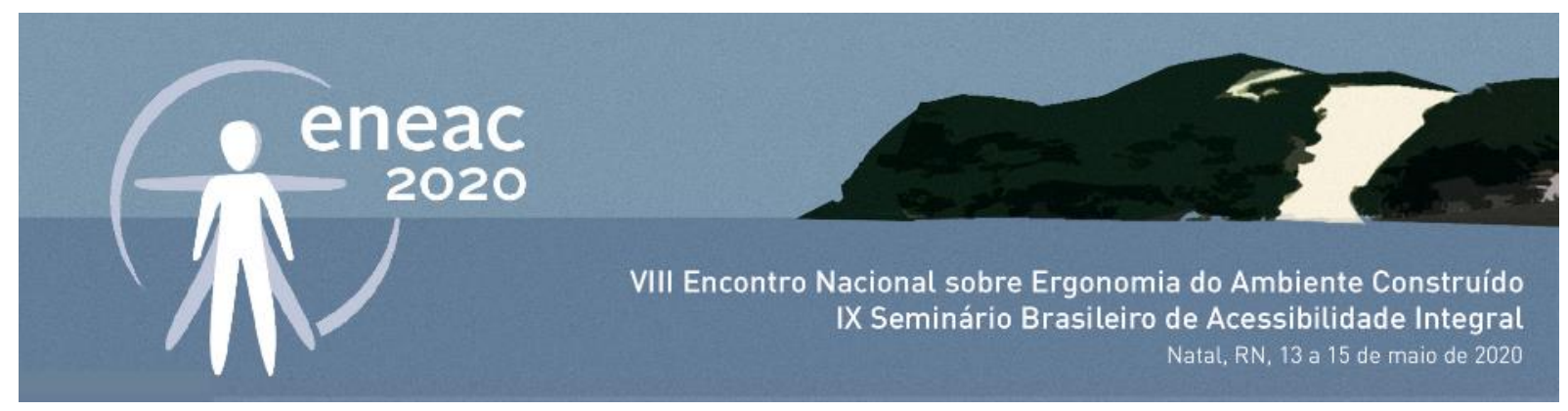

a case study the Pici University campus at UFC, located in Fortaleza, with the purpose of evaluating the infrastructure and its impact on the reception of students with disabilities. The field research is based on empirical and qualitative methodologies from three different perspectives: "Exploratory Walkthrough" (RHEINGANTZ et al, 2009) through observation of the campus, "Technical-Functional Evaluation" (ORNSTEIN, ROMERO 1992) based on the parameters established in NBR9050/2015, NBR16537/2016, Decree 5.296/2004, among others, and finally, "Accompanied Tour" (DISCHINGER, 2000) from the perception of students with disabilities. The results present the current situation of an IFES in the face of the challenges to guarantee the access of these students and some recommendations for renovation and construction of accessible campuses.

KEYWORDS: Accessibility; University spaces; Federal University of Ceara; Quota law

\section{INTRODUÇÃO}

No Brasil, o quadro segregatício de exclusão de pessoas com deficiência impôs uma série de barreiras que historicamente obstaculizou o acesso destas populações ao exercício do direito à educação. Esta disfunção inicia-se na educação básica, porém agrava-se no ensino superior, em que se observa um distanciamento proporcional alarmante entre o número de matrículas de pessoas com e sem deficiência. A lacuna relativa ao ingresso de pessoas com deficiência à educação e mais especificamente ao ensino superior no Brasil contribui para dificultar o acesso ao mercado de trabalho qualificado e tende a reforçar um quadro de vulnerabilidade social desta população, estabelecendo um paralelo entre deficiência e fragilidade social.

O acesso de pessoas com deficiência ao ensino regular no Brasil engendra apenas nas últimas décadas os primeiros passos para a concretização deste direito. Na década de 1990, transformações no sistema educacional apontam no sentido de regulamentar a inclusão de pessoas com deficiência na educação básica. Posteriormente, a partir do final dos anos 1990, surgem os prelúdios de iniciativas que tratassem da inclusão destas pessoas no ensino superior.

Apesar destes avanços, o Censo Demográfico de 2010 apresentou um dado crítico: 61,1\% das pessoas com deficiência com 15 anos ou mais de idade e que declararam ter pelo menos uma das deficiências investigadas pelo IBGE não possuem instrução ou possuem apenas ensino fundamental incompleto e apenas 6,7\% possuem ensino superior completo (IBGE, 2012). O Instituto Nacional de Estudos e Pesquisas Educacionais Anísio Teixeira (Inep) vem observando, por meio dos Censos da Educação Superior, um sequencial aumento do número de matrículas de pessoas com deficiência em instituições de ensino superior, porém, o cenário ainda está aquém do razoável.

A "Lei de cotas" (Lei 12.711/2012) contribuiu para melhorar este cenário ao reservar, nos concursos seletivos para ingresso nos cursos de graduação, no mínimo 50\% (cinquenta por cento) de suas vagas para estudantes que tenham cursado integralmente o ensino médio em escolas públicas, sendo $50 \%$ destas reservadas aos estudantes oriundos de famílias com renda igual ou inferior a 1,5 saláriomínimo per capita. Ainda que de forma não específica, pessoas com deficiência foram beneficiadas 


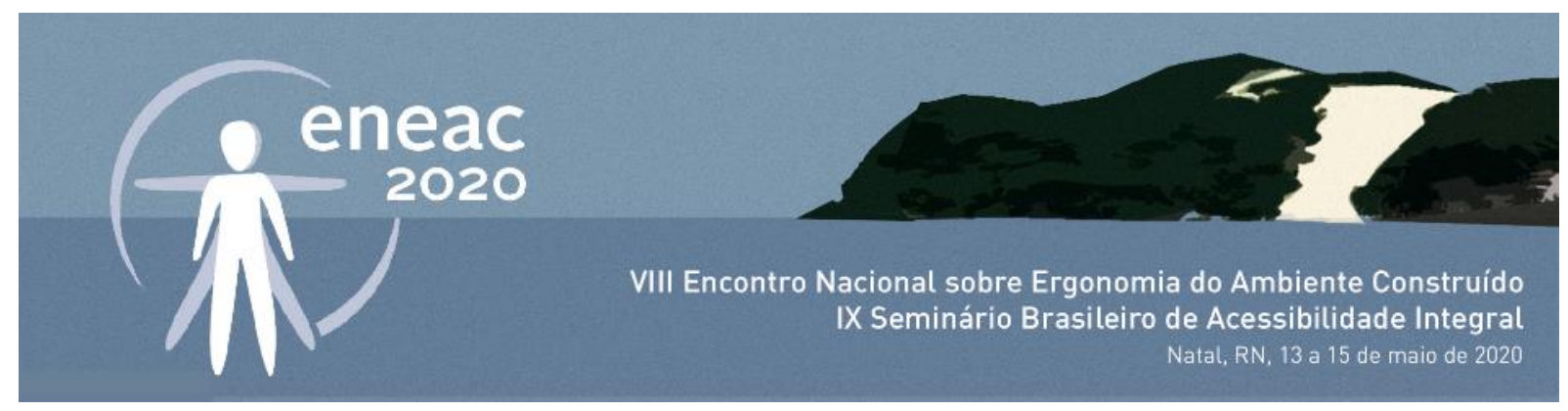

por esta política, pois, conforme apresentado, há uma relação estreita entre deficiência e classes sociais financeiramente mais vulneráveis.

Mais recentemente, um novo marco legal surge com a sanção da Lei 13.409 de 28 de dezembro de 2016, que incluiu a reserva de vagas para pessoas com deficiência na "Lei de cotas". Esta mudança de paradigma busca de forma específica acelerar o processo de inclusão de pessoas com deficiência no ensino superior a fim de equiparar as oportunidades por meio da "igualdade material", ou seja, a grupos sociais diferentes são ofertados caminhos diferentes para se chegar a meios igualitários.

Com a aplicação da Lei 13.409/2016, houve um aumento considerável no ingresso de estudantes com deficiência na UFC. Em 2017, a Secretaria de Acessibilidade - UFC Inclui contabilizava 88 estudantes com deficiência na UFC, oriundos de vários semestres dos anos anteriores. Considerando apenas os ingressos de 2018, quando pela primeira vez foi efetivada a Lei, foram 204 novas matrículas de estudantes com deficiência, evidenciando um ponto de inflexão nestes acessos.

As reservas de vagas no ensino superior representam um grande avanço para as pessoas com deficiência no que diz respeito à equiparação de direitos, porém nos coloca uma reflexão: as instituições federais de ensino superior encontram-se estruturalmente preparadas para o ingresso destes estudantes? Neste contexto, a pesquisa teve o objetivo de avaliar as condições de acessibilidade espacial no estudo de caso do campus do Pici da Universidade Federal do Ceará em Fortaleza com enfoque em percursos e ambientes de maior uso pelos estudantes com deficiência.

Dada a inviabilidade de analisar todos os percursos do campus, optou-se por delimitar uma rota específica de aproximadamente 1,5km. Esta rota, denominada neste estudo de "percurso prédefinido", buscou contemplar as edificações de maior relevância e com maior potencial de fluxos de estudantes com deficiência: o Restaurante Universitário, o Instituto de Cultura e Arte (ICA), o Auditório do Centro de Ciências (CC), a Biblioteca Central e o Centro de Convivência da UFC, sendo denominadas neste estudo de "edificações-chave".

A análise do campus em estudo desenvolveu-se a partir de três perspectivas: "walktrough exploratórias" (RHEINGANTZ et al, 2009), ou seja, observação em visitas de campo, "avaliação técnico-funcional" (ORNSTEIN, ROMERO, 1992) realizada pelo pesquisador com a colaboração de estudantes da disciplina de Desenho Universal da graduação do curso de Arquitetura e Urbanismo da UFC, por meio de fichas de análise, tendo como critérios principais os parâmetros estabelecidos na NBR9050/2015, NBR16537/2016, Decreto 5.296/2004, entre outros estabelecidos nas regulações específicas, bem como dos discursos de estudantes com deficiência da UFC apreendidos em "passeios acompanhados" (DISCHINGER, 2000), que consistiu em caminhar pelo "percurso prédefinido" e "edificações-chave" e, simultaneamente, por meio de entrevistas, registrar os relatos das vivências e as percepções destes estudantes no espaço.

Foram realizados 6 "passeios acompanhados", 3 com estudantes com deficiência física (sendo uma estudante em cadeira de rodas motorizada, um estudante em cadeira de rodas motorizada e uma estudante em cadeira de rodas manual) e 3 com estudantes com deficiência visual (sendo um estudante com baixa visão e dois estudantes cegos). A pesquisa foi submetida, por meio da 


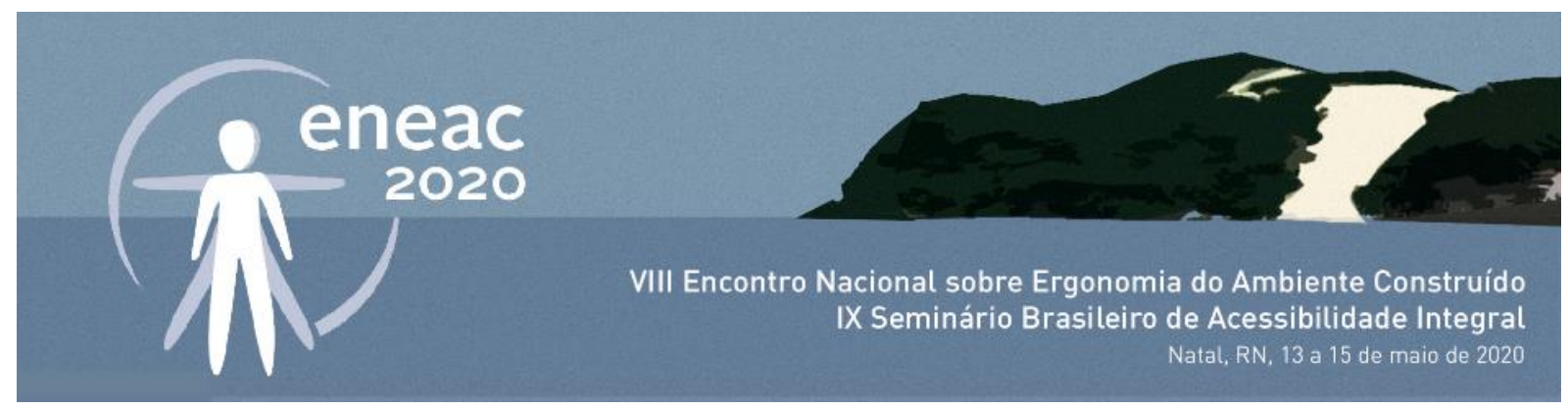

Plataforma Brasil, ao Comitê de Ética e Pesquisa da Universidade Federal do Ceará - CEP-

UFC/PROPESQ-UFC, obtendo aprovação conforme PARECER CONSUBSTANCIADO número 3.262.851.

\section{ACESSIBILIDADE NO CAMPUS UNIVERSITÁRIO BRASILEIRO}

O espaço universitário é reconhecido como um paradigma de democracia, devendo permitir o acesso de todos os segmentos da sociedade a todos os setores e níveis de ensino e pesquisa (DUARTE, COHEN, 2004). A "inclusão espacial" (DUARTE, COHEN, 2004) de todas as pessoas, incluindo pessoas com deficiência, deve, portanto, ser a premissa primordial na configuração destes espaços. A realidade, porém, nos mostra contradições.

No Brasil, o ensino superior inicia com a chegada da família real portuguesa no início do século XIX, originalmente na forma de cátedras isoladas voltadas à formação profissional de influência europeia, estruturadas em edificações isoladas instaladas nos centros das cidades. $O$ surgimento das primeiras universidades no Brasil remonta os anos 1920 e 1930, a partir da justaposição de faculdades existentes e inseridas, portanto, dentro da malha urbana das cidades, a exemplo da Universidade Federal do Rio de Janeiro (1920), Universidade de São Paulo (1934) e Universidade Federal do Rio Grande do Sul (1934) (PINTO, BUFFA, 2009).

Neste primeiro momento, destaca-se a promulgação do "Estatuto das Universidades Brasileiras" em 1931, que estabelecia padrões de organização para as instituições e influenciou a estruturação universitária nos 30 anos seguintes (OLIVEIRA, 2005). Neste contexto, começava a ganhar força o anseio pela integração acadêmica e pela unificação espacial como forma de superar o modelo de simples reunião de escolas superiores, o que vem a se materializar nos primeiros campi do Brasil. Estes novos espaços tiveram grande influência das instituições norte-americanas, que inspiradas em modelos britânicos, inovam ao criar o conceito de campus universitário. Se na tradição europeia as universidades eram essencialmente urbanas, nas colônias norte-americanas, estas foram preferencialmente dispostas nos limites da cidade ou mesmo no campo e passaram a ser pensadas como cidades, com edifícios separados e implantados em espaços verdes e abertos.

Estes primeiros espaços universitários construídos já seguiam as premissas do modelo norteamericano e foram designados com a terminologia de "cidades universitárias" (UFRJ e USP). Nos Estados Unidos, porém, o modelo implantado tornou-se um organismo de grande autonomia, distanciado dos centros urbanos e constituído tanto por ambientes acadêmicos e administrativos, como por espaços para moradia de professores e estudantes, além de serviços, equipamentos, configurando-se como pequenas cidades. A utilização do termo "cidade universitária" representa uma aspiração destas primeiras universidades brasileiras de criar um espaço isolado para abrigar atividades acadêmicas, de moradia, e que oferecesse todos os serviços da cidade regular, o que não ocorreu no Brasil.

A ideia do campus universitário ganha força em um segundo momento que se inicia nos anos 1960. Esta fase é caracterizada por intensas transformações no cenário político (golpe militar de 1964) e pelo nacional-desenvolvimentismo, com forte apelo ao desenvolvimento cientifico e tecnológico. 


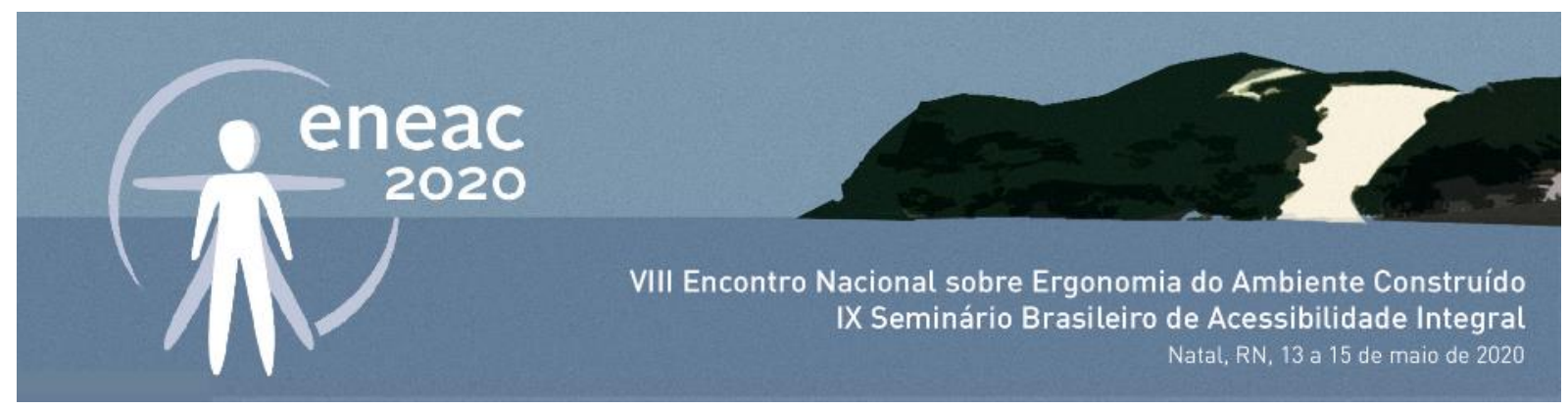

Neste turbulento contexto, ocorre a restruturação da organização universitária: a modernização da universidade brasileira e o surgimento de diversos campi universitários. O consultor norte-americano Rudolph Atcon visitou 12 universidades brasileiras em 1965, cujo diagnóstico e medidas para modernização das instituições foi registrado na publicação "Rumo a Reformulação Estrutural da Universidade Brasileira" de 1966, também conhecido como "Relatório Atcon", e que juntamente com o "Relatório Meira Mattos (1968)" dá subsídios para a concepção da Reforma Universitária de 1968 (Lei № 5.540, de 28 de novembro de 1968). A Reforma Universitária extingue as tradicionais cátedras, institui uma estrutura acadêmica com base em departamentos, o modelo de disciplina/créditos e preconiza uma grande expansão da universidade pública brasileira, na qual passou-se a priorizar a construção de campi universitários.

A figura de Atcon aparece mais uma vez na concepção de um documento-chave para a expansão das universidades, o "Manual para o planejamento integral do campus universitário" publicado pelo Conselho de Reitores das Universidades Brasileiras (CRUB) em 1970. Este documento tinha por objetivo orientar a implementação estrutural da reforma universitária, através do planejamento dos campi universitários existentes ou a serem construídos. O Manual baseia-se em um conceito biológico de universidade como organismo vivo e flexível, na integralidade e na máxima racionalidade, ou seja, na criação de uma "máquina de estudar e pesquisar" (PINTO, BUFFA, 2009). Determina regras para a aquisição de terreno, estabelece uma rígida "zonificação" e cria parâmetros e diretrizes para urbanização, paisagismo, tipologias de edifícios, entre outros. Quanto aos edifícios, Atcon advoga pela máxima racionalidade e propõe a criação de edifícios fixos (biblioteca, estádio, piscina, teatro) associados a estruturas flexíveis (e até removíveis) na forma de pavilhões. Esta arquitetura procurava responder ao novos princípios da modernização das universidades brasileiras: racionalização, flexibilidade, expansão e integração.

Em linhas gerais, os campi brasileiros foram implantados com grande influência do pensamento de máxima racionalidade do urbanismo moderno, através do zoneamento funcional de áreas do conhecimento e da hierarquia viária que priorizou o veículo em detrimento do pedestre, distanciando a estrutura da escala humana e desfavorecendo a caminhabilidade. Este modelo de campus, pautado por uma visão mecanicista e utilitária concentrou os investimentos na consolidação dos ambientes de ensino e pesquisa, desprezando os locais de convergência, de convivência, das relações informais, dos encontro casuais e de permanência informal (OLIVEIRA, 2005, p.33).

A influência do modelo norte-americano repercutiu na utilização de vastas porções de terreno com edifícios isolados, o que, em muitos casos, prejudicou a acessibilidade espacial ao ampliar demasiadamente as distâncias, desfavorecendo os deslocamentos a pé, bem como a usabilidade e apropriação dos espaços comuns. A exemplo deste aspecto, torna-se representativo o caso da Universidade de Brasília (Unb), em que os generosos afastamentos dos edifícios propostos por Lúcio Costa geraram espaços ermos, sem vida, e que foram posteriormente adensados:

A ocupação com longos afastamentos dos edifícios acabou por revelar um espaço com aspecto despovoado e de difícil circulação. As áreas de vivência não eram utilizadas e o aspecto de desolamento prevalecia. A alternativa foi redirecionar o plano de ocupação no sentido de adensar as massas dos 


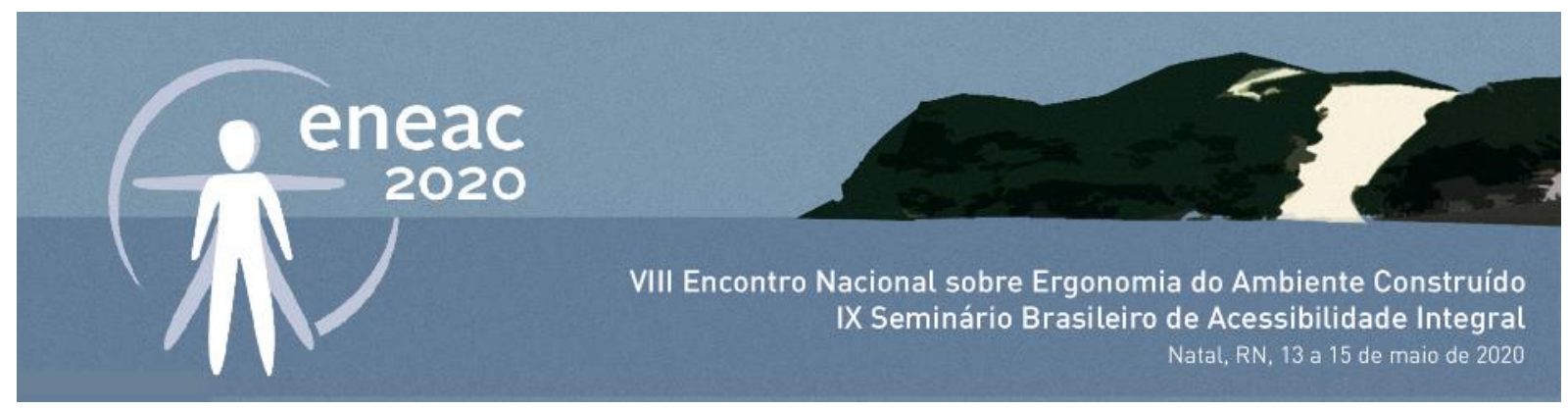

edifícios, implantando os prédios com menos distâncias entre eles e ocupando os grandes vazios existentes com os novos edifícios. (PINTO, BUFFA, 2009, p. 127)

A arquitetura dos campi brasileiros, sobretudo a partir dos anos 1970, é marcada pela extrema racionalidade expressa em modulações e padronizações, resultando em edifícios semelhantes ou iguais para usos diversos e que dificultam a identificação e orientação dos usuários. Soma-se que os atributos ambientais, ou "affordances" (GIBSON, 1986), negligenciam os sentidos em espaços estéreis, impessoais, por vezes demasiadamente amplos e sem referências, contribuindo para desestimular o "percorrer", o "permanecer" e o "conviver". As implantações de setores habitacionais (quando existentes), dispostas em áreas periféricas, e a desatenção com as convergências de fluxos e implantação de serviços reduz a atratividade dos espaços comuns e contribuem para reduzir o campus a "lugar de trabalho e passagem" (PINTO, BUFFA, 2009).

Quanto à acessibilidade espacial, acrescenta-se que grande parte da infraestrutura das universidades brasileiras foi concebida e construída em décadas anteriores à legislação que trata da pauta, impondo barreiras arquitetônicas e urbanísticas que limitam o acesso e a permanência de pessoas com deficiência no ensino superior. As primeiras intervenções no sentido de fazer acontecer a acessibilidade espacial nas universidades foram pontuais e motivadas pelo acesso, ainda que pouco frequente, de estudantes com deficiência nestas instituições. Estas incipientes adaptações, em sua maioria construções de rampas, adaptações de banheiros, adaptações de vãos e portas, visavam apenas sanar um "problema" pontual: o acesso de um determinado estudante à sala de aula, enquanto grande parte dos demais espaços, inclusive de uso comum, continuavam inacessíveis.

Somente a partir dos anos 1990, a luta por direitos das pessoas com deficiência, bem como a evolução do pensamento social sobre acessibilidade e inclusão tem seu rebatimento na criação de uma base legal e normativa que passa a pregar a adaptação dos espaços existentes e construções de espaços acessíveis. No caso das Instituições de Ensino Superior (IES), o Aviso Curricular no 277 de 1996 do Ministério da Educação (MEC) orienta os reitores destas instituições a criar condições para possibilitar o acesso destes estudantes ao 3o grau. A partir daí, surgem paulatinos avanços. A Portaria n.o 1.679 de 1999 e posteriormente a Portaria no 3.284 de 2003, sancionadas pelo MEC, dispõem sobre requisitos de acessibilidade para autorização e reconhecimento de cursos (tomando como base, na questão espacial, a Norma Brasileira 9050 da ABNT).

No início do século XXI, novas mudanças trazidas pela legislação e ações do Ministério Público impulsionam transformações significativas na infraestrutura das universidades voltadas à melhoria das condições de acessibilidade espacial. Destaca-se a publicação da Lei 10.098 de 2000 e o Decreto $5.296 / 2004$, considerado um importante marco regulatório no que diz respeito à promoção da acessibilidade, e que determina que os estabelecimentos de ensino de qualquer nível deverão proporcionar condições de acesso e utilização de todos os seus ambientes para pessoas com deficiência. Políticas afirmativas importantes foram estabelecidas a exemplo do Projeto Incluir que, a partir de 2005, concedeu recursos financeiros para execução de ações de acessibilidade nas Instituições Federais de Ensino Superior (IFES), incluindo eliminação de barreiras arquitetônicas. 


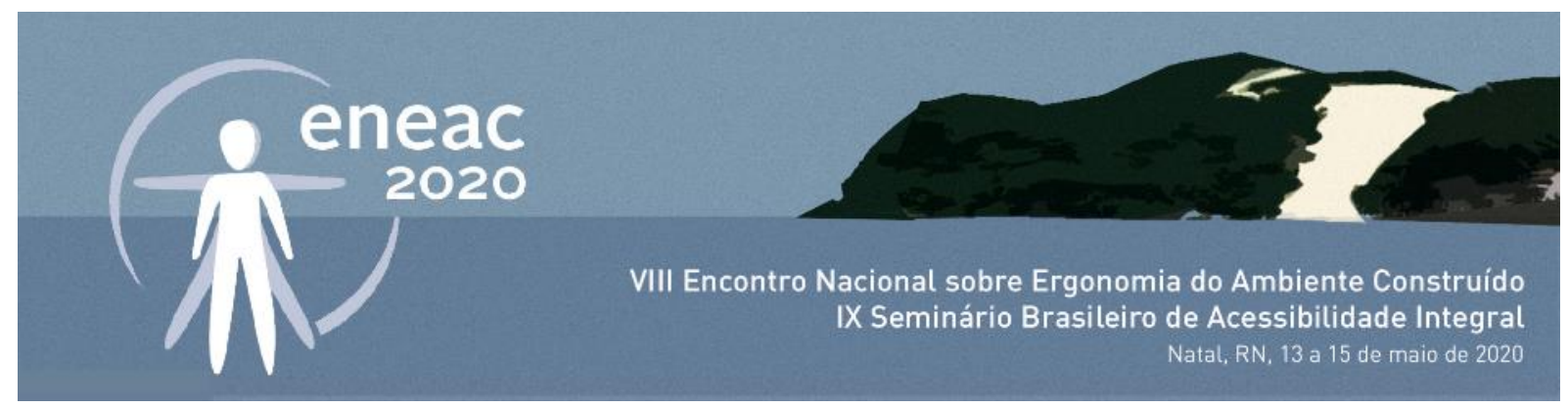

Assim, o contexto atual apresenta uma nova fase das IFES, em que as barreiras arquitetônicas e urbanísticas foram em parte superadas, porém muitas lacunas de diversas ordens permaneceram neste processo, configurando um cenário ainda distante do ideal. O modo como muitas intervenções de acessibilidade nos campi brasileiros foi pensado, diante do imediatismo em atender as demandas com o mínimo de recursos, resultou em soluções por vezes reducionistas, balizadas pelo traço técnico da simples tentativa de aplicação dos padrões mínimos das regulações. Num entendimento mais holístico da acessibilidade, entendemos que os espaços concebidos apenas em função da sucessão de dispositivos técnicos (barras, rampas, pisos táteis etc.), podem não garantir "Acessibilidade Plena", ou seja, a "capacidade do lugar de acolher seus visitantes e criar aptidão no local para desenvolver empatia e afeto em seus usuários" (DUARTE, COHEN, 2012). O pensamento paliativo da acessibilidade, utilizada para resolver um "problema" de um determinado grupo social, ou seja, dissonante do conceito do desenho universal, que busca uma qualidade espacial para a ampla população, pode resultar em soluções segregacionistas: "até que ponto essas iniciativas, em lugar de eliminar, não acabam reforçando o sentimento de exclusão?" (CAMBIAGHI, 2007, p. 62).

Quando consideramos a realidade de pessoas com deficiência ou mobilidade reduzida, o campus universitário brasileiro mostra-se um ambiente de riscos e desafios que dificultam o processo de "Moldagem do Lugar", conceito desenvolvido por Duarte (1993) para descrever o processo através do qual o ambiente é percebido, ganha significados e passa a ser "Lugar", definido como algo seguro onde estão imbricados valores e relação de proximidade (TUAN, 1983). A construção afetiva do campus enquanto "Lugar" fundamenta-se na percepção ambiental e na acessibilidade como uma condição de qualidade ambiental que deve exceder os parâmetros numéricos, considerar a escala humana e seus sentidos, promover o desenho universal, a caminhabilidade, o afeto, o convívio e, enfim, a inclusão. A realidade é que ainda estamos caminhando nesta construção, que nos parece ainda distante de um campus plenamente acessível a todos.

\section{ESTUDO DE CASO: O CAMPUS DO PICI}

O campus do Pici, equipamento da Universidade Federal do Ceará situado em Fortaleza, é constituído por uma grande gleba de 212 hectares com estrutura viária própria (independente da cidade) e edifícios separados, implantados em vastos espaços livres. Além das premissas do modelo de campus norte-americano, é latente a influência da racionalidade presente no urbanismo moderno: o zoneamento funcional das áreas do conhecimento e a hierarquia viária, priorizando o veículo em detrimento das circulações de pedestre. O campus possui áreas agradáveis e com potencial para criação de áreas públicas de qualidade, principalmente devido aos recursos naturais, contribuindo para a configuração de um microclima favorável ao "caminhar" e "permanecer".

As constantes demandas por construções, reformas e ampliações de ambientes didáticos no campus, somadas à inconstância e escassez de recursos, resultou em uma configuração espacial em que, além do sistema viário básico, foi priorizada a construção de edifícios, em detrimento dos percursos e seus interstícios, em muitos casos, ocupados por estacionamentos. Os poucos espaços de convivência 


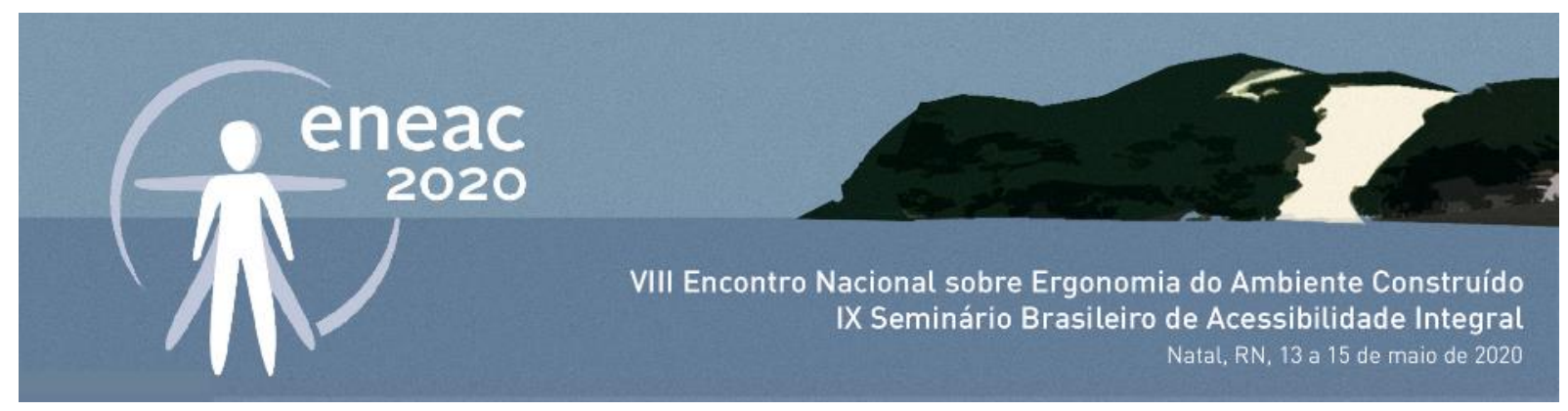

existentes no campus são dispersos, com infraestrutura precária e possuem muitos problemas de acessibilidade, excluindo assim, parte de seus usuários.

A exemplo da cidade moderna, fordista, pensada para uma sociedade industrial, a excessiva racionalidade e modulação marcou a arquitetura de muitos edifícios no campus. A padronização de edifícios resultou em alguns espaços semelhantes e que dificultam a identificação e orientabilidade, a que se soma a carência de infraestrutura, a escassez de serviços e a ausência de setores habitacionais. Quando consideramos o acesso e a permanência de pessoas com deficiência ou mobilidade reduzida aos espaços universitários do Pici, esta realidade torna-se ainda mais hostil, pois as inadequações de acessibilidade espacial da infraestrutura, em grande parte concebida anteriormente ao surgimento das legislações e normatizações específicas que tratam da pauta, dificultam ou impossibilitam a concretização da "inclusão espacial” (DUARTE, COHEN, 2004).

A partir dos anos 1990, com o surgimento de uma nova base legal e normativa e do entendimento dos direitos das pessoas com deficiência, iniciaram pressões externas de órgãos de controle, bem como da própria comunidade, para adaptar os espaços construídos da UFC. Estas respostas se deram de várias formas ao longo do tempo, sendo a ação mais significativa o Plano de Acessibilidade para os três campi de Fortaleza. O Plano de Acessibilidade para o campus do Pici provocou uma série de transformações espaciais internas e externas aos edifícios. Nos blocos, buscou-se solucionar os acessos, houve recuperação de pavimentações, adaptações e construções de sanitários acessíveis, construção de rampas, instalação de plataformas e ampliação do vão de portas. Nas áreas externas, houve um esforço em criar calçadas acessíveis que deram uma nova qualidade a muitos trechos e foram criadas vagas reservadas em estacionamentos para pessoas com deficiência. Entretanto, devido à enorme defasagem de acessibilidade no campus, mesmo após a realização destas obras, muitas lacunas perduram e dificultam ou inviabilizam o pleno uso dos espaços por pessoas com deficiência, conforme verifica-se nas observações, vivências e relatos desta pesquisa.

Dos quatro acessos existentes no campus, apenas um deles (Avenida Humberto Monte) permite a entrada de pessoas em cadeiras de rodas pela calçada. Existe interrupção da calçada nos acessos da Rua Padre Guerra e Rua Pernambuco. O acesso da Avenida Mister Hull é realizado apenas por escadaria sem concordância de nível por rampa ou equipamento eletromecânico (ver Figura 1). Com exceção do acesso da Avenida Humberto Monte, os demais possuem um distanciamento em relação à rota do ônibus interno, cujos percursos de ligação não constituem rotas acessíveis.

No campus, foram constatados muitos trechos sem calçadas ou vias com calçada em apenas um dos lados, além de inadequações em calçadas existentes: pavimentação quebrada ou piso irregular (gerando trepidações em cadeiras de rodas), desníveis, ausência ou descontinuidade de rebaixos, vegetação invadindo a faixa livre, areia cobrindo a calçada (ver Figura 2). Também há inadequações e descontinuidades nas travessias, iluminação pública insuficiente em muitos trechos e inadequações ou ausência de sinalizações de vagas reservadas. Acrescenta-se que, em muitos casos, a execução de projetos isolados no campus não se comunica para estabelecer rotas acessíveis com relação aos demais blocos, criando por vezes ilhas "acessíveis" apartadas. 


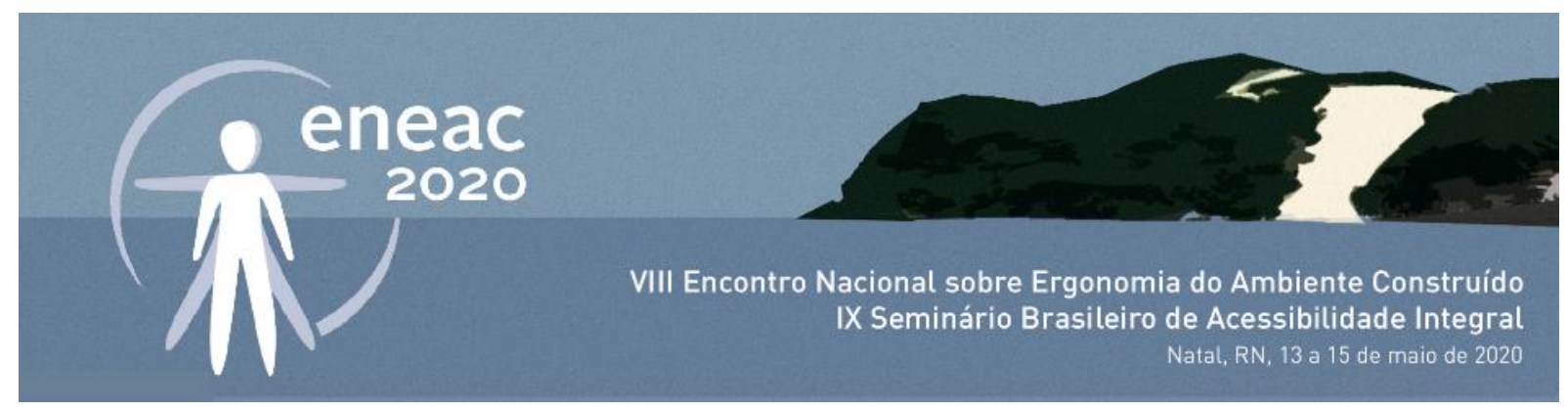

Com base nas observações, vivências e relatos dos estudantes com deficiência, destacamos duas constatações críticas: as pessoas em cadeiras de rodas frequentemente trafegam pela pista de rolamento nas vias do campus, disputando o espaço com veículos, devido às descontinuidades em percursos e travessias (ver Figura 3). Estas vivências e relatos mostram ainda que, a despeito da condição de restrição de mobilidade: estudantes com deficiência frequentemente realizam trajetos mais longos do que pessoas sem deficiência para chegar a um mesmo local devido aos problemas de acessibilidade no campus.

Figura 1 - Acesso da Avenida Mister Hull (esquerda) / Figura 2 - Descontinuidade de percurso com calçada quebrada (centro) / Figura 3 Pessoa em cadeira de rodas transitando pela pista de rolamento (direita).
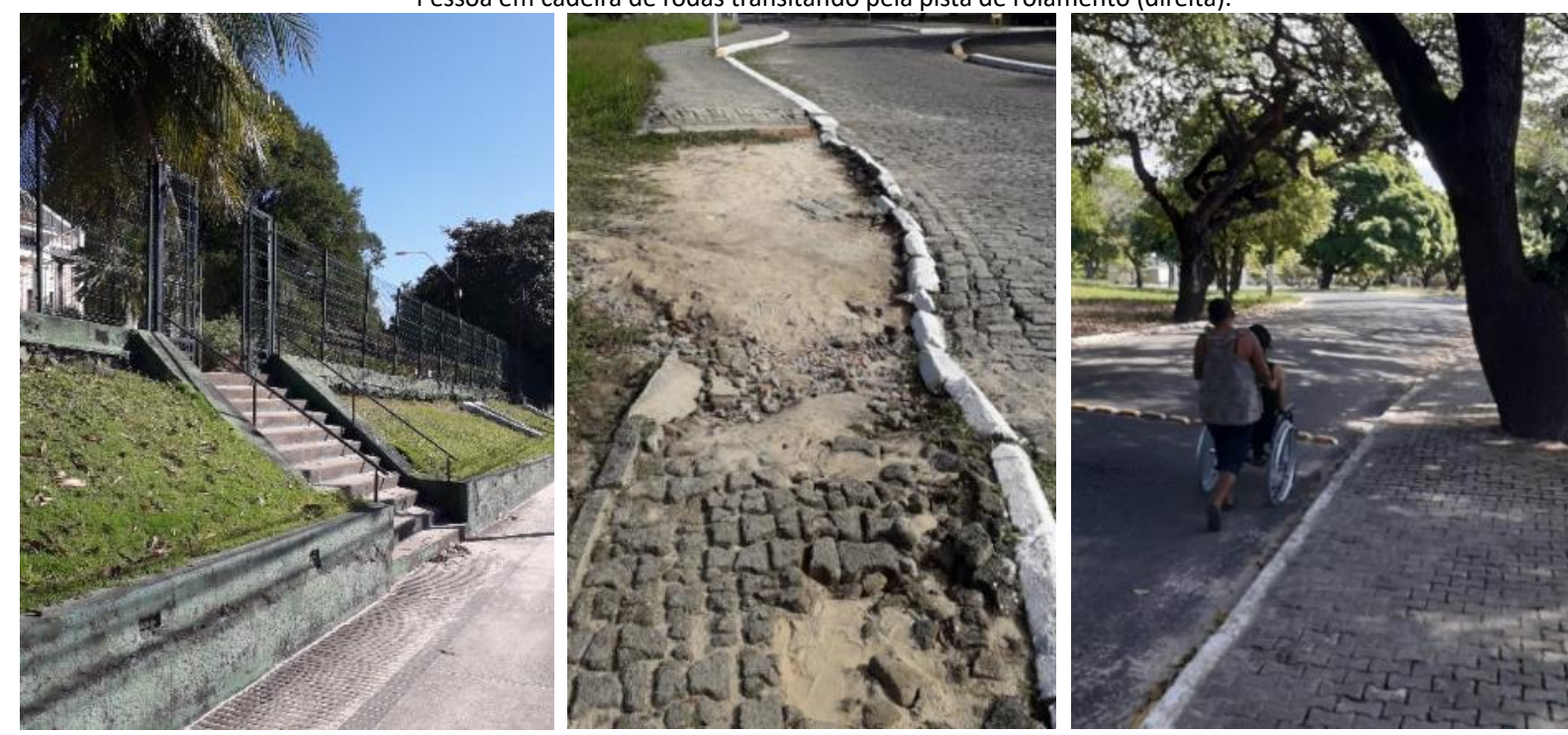

Fonte: Acervo da pesquisa (2019).

A análise do "percurso pré-definido" evidencia na prática as dificuldades de circulação nas áreas externas do campus. Na Figura 4, utilizou-se um padrão de cores para ilustrar, em uma visão geral, as dificuldades encontradas pelos estudantes com deficiência durante a realização deste percurso. Neste mapa, a cor vermelha designa locais em que houve grande dificuldade ou mesmo um impedimento de passagem. A cor amarela designa locais com moderada dificuldade e a cor verde, locais com pouca ou nenhuma dificuldade.

Observa-se, numa leitura geral, a predominância de pontos vermelhos e amarelos, evidenciando as más condições ou atendimento parcial à acessibilidade. Quanto à mobilidade de pessoas com deficiência visual, público que apresenta o maior percentual de pessoas com deficiência no Brasil, constatou-se como um ponto alarmante com predominância de pontos vermelhos devido à ausência de rota visual/tátil e às situações de risco sem a sinalização adequada: objetos suspensos, vegetação, risco de queda. Os poucos pontos verdes e amarelos referem-se a locais onde foram utilizadas referências edificadas para balizamento destes percursos como muros, guias, canteiros, sendo estas descontínuas. 


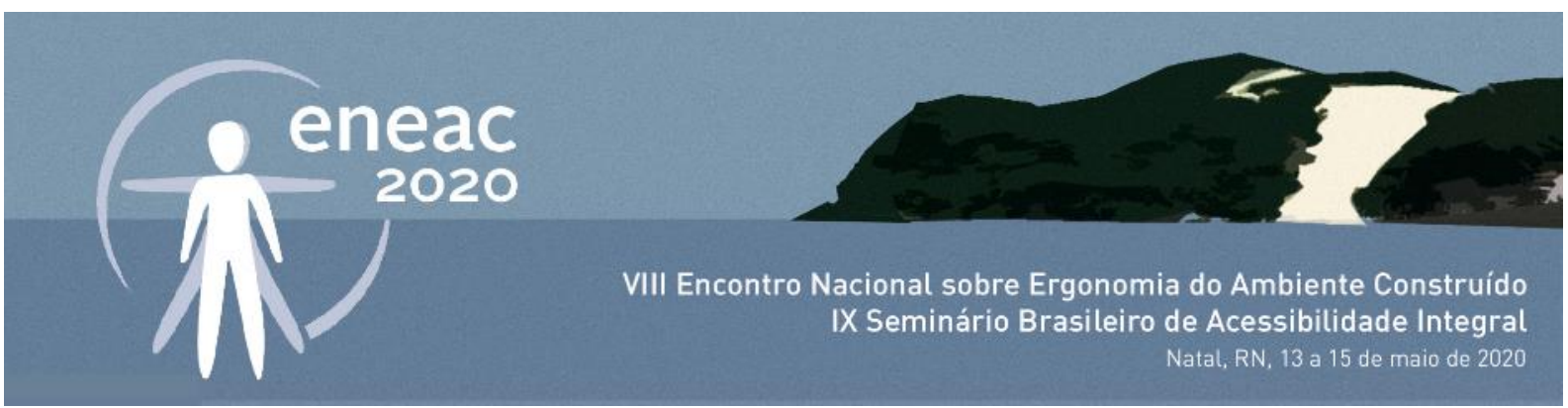

Figura 4 - Mapa do "percurso pré-definido" com indicação do nível de dificuldade de circulação pelos estudantes com deficiência.

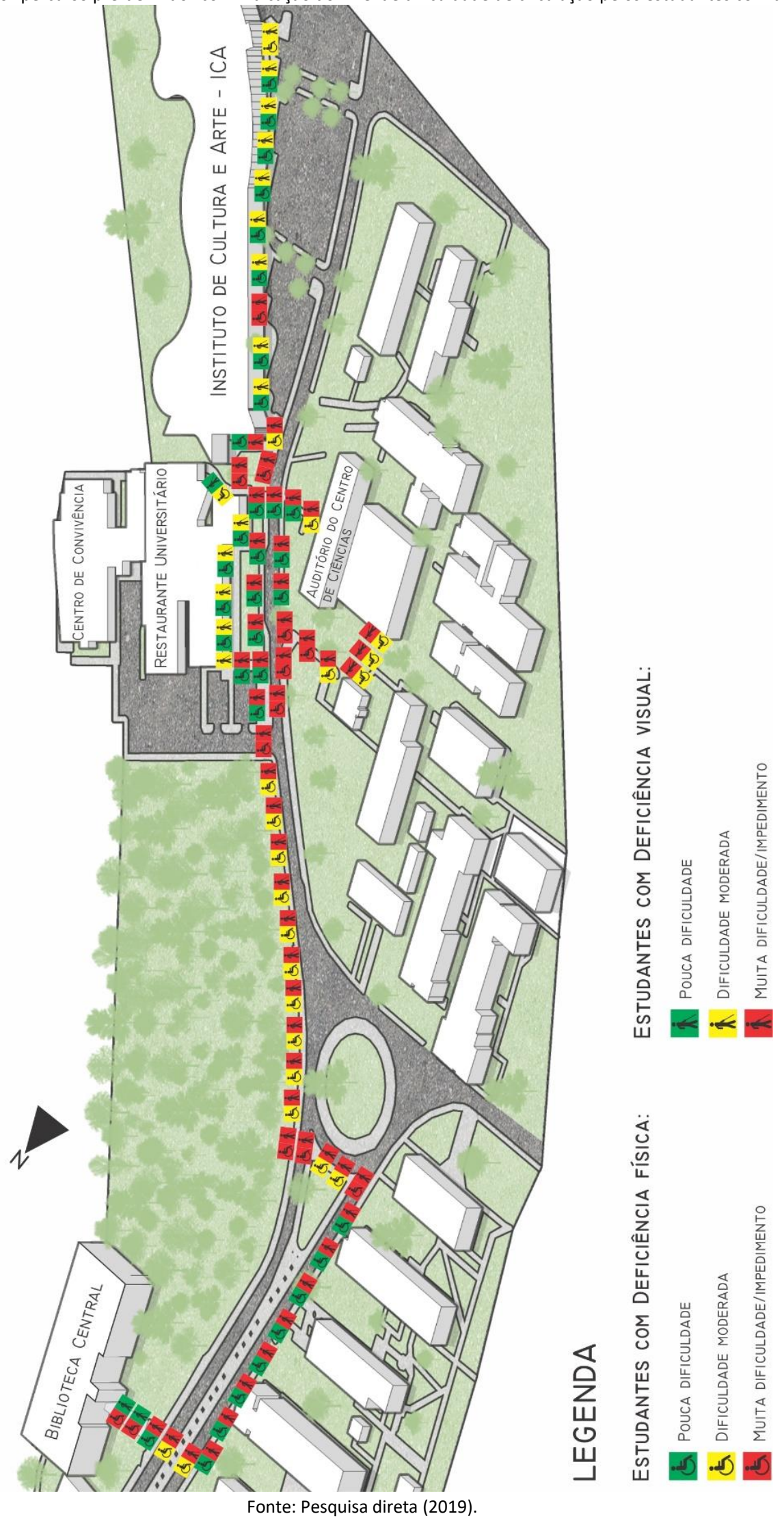




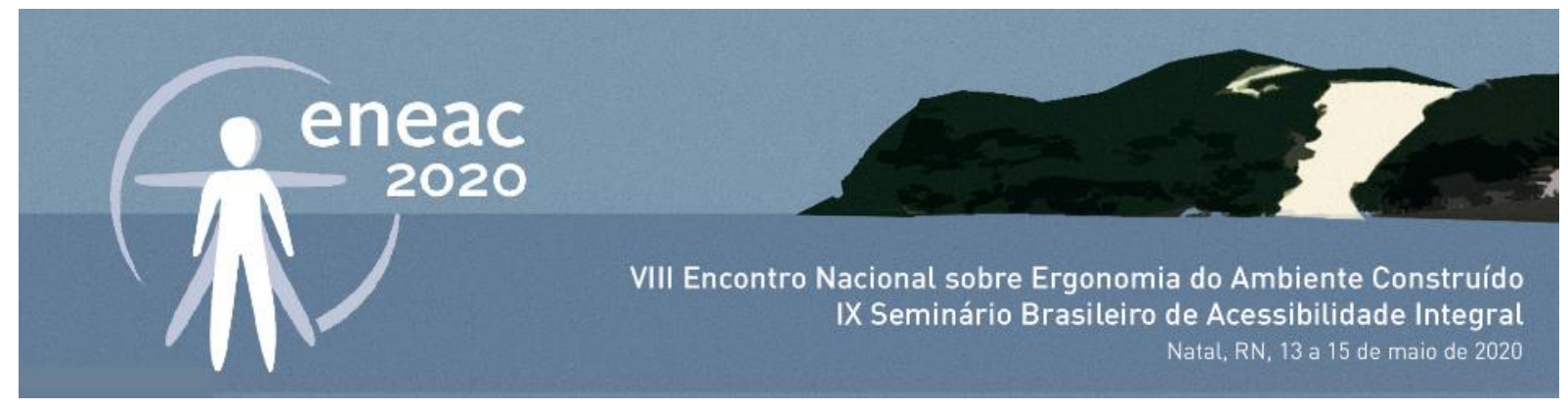

Acrescenta-se que não existe mapa visual/tátil do campus, nem informações acessíveis sobre a rota do ônibus interno. No caso dos trajetos realizados pelos estudantes em cadeiras de rodas, observa-se na Figura 4 um maior número de pontos verdes e amarelos em relação aos estudantes com deficiência visual, devido às condições satisfatórias em alguns trechos de calçada. Alguns locais, entretanto, a exemplo das travessias, representam pontos críticos no deslocamento destes estudantes.

Quanto aos edifícios do campus, no Quadro 1 foram dispostos alguns critérios básicos avaliados nas "edificações-chave" com objetivo de apresentar uma visão geral das condições de acessibilidade espacial. Utilizou-se o mesmo padrão de cores da Figura 4: a cor vermelha designa locais em que houve grande dificuldade ou mesmo um impedimento de acesso ou uso. A cor amarela designa locais com moderada dificuldade e a cor verde, locais com pouca ou nenhuma dificuldade.

\begin{tabular}{|c|c|c|c|c|c|}
\hline EDIFICAÇÕES & Biblioteca Central & Restaurante & Centro de & Instituto de & Auditório CC \\
\hline Critérios & & Universitário & Convivência & Cultura e Arte & \\
\hline \multicolumn{6}{|l|}{ Acessos } \\
\hline \multicolumn{6}{|l|}{ Vagas reservadas } \\
\hline \multicolumn{6}{|l|}{ Circulação horizontal } \\
\hline \multicolumn{6}{|l|}{ Sinalização visual/tátil } \\
\hline Circulação vertical & & Ñ/aplica & & & Ñ/aplica \\
\hline \multicolumn{6}{|l|}{ Sanitários acessíveis } \\
\hline Balcões & & & & & Ñ/aplica \\
\hline Bebedouros & & & & & Ñ/aplica \\
\hline \multicolumn{6}{|l|}{ Mobiliário } \\
\hline \multicolumn{6}{|l|}{ LEGENDA: } \\
\hline \multicolumn{6}{|c|}{ Pouca dificuldade de acesso ou uso } \\
\hline \multicolumn{6}{|c|}{ Dificuldade moderada de acesso ou uso } \\
\hline \multicolumn{6}{|c|}{ Muita dificuldade/impedimento de acesso ou uso } \\
\hline
\end{tabular}

Os resultados apresentados no Quadro 1 assemelham-se aos da Figura 4, com predominância de pontos vermelhos e amarelos, evidenciando as más condições ou atendimento parcial à acessibilidade, cujos casos críticos foram destacados abaixo:

- Na questão dos acessos, destaca-se o prédio da Biblioteca cuja rampa de acesso ao térreo configura situação de risco ou muita dificuldade devido à inclinação excessiva (ver Figura 5). Destaca-se ainda o Auditório do CC, com acesso principal realizado por escadarias (ver Figura 8).

- Quanto às vagas reservadas em estacionamentos, a predominância da cor amarela evidencia a existência destes espaços, porém, em geral, com inadequações de sinalização. No caso do ICA, a situação de risco ocasionada por uma grelha de concreto no rebaixo da calçada junto às vagas $e$ a quase total ausência de sinalização acarretam maior dificuldade de acesso e uso (ver Figura 9).

- Quanto às circulações horizontais, predomina a cor verde, com exceção do Restaurante Universitário, que apresenta boas condições em geral, porém com desníveis no acesso dos 


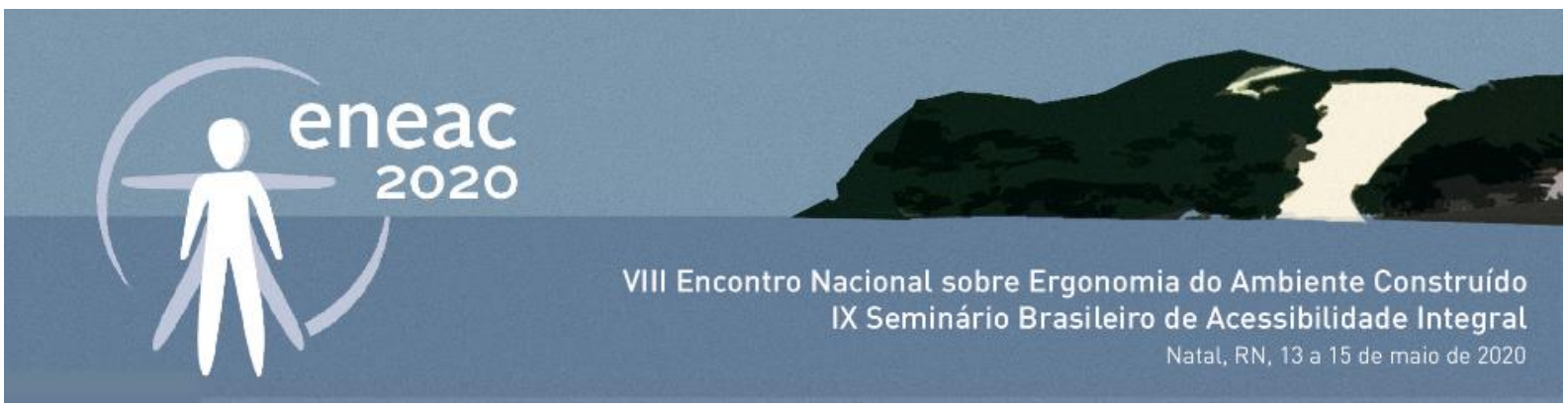

sanitários coletivos. Destaca-se ainda o Auditório do CC, que embora também possua boas condições de circulação em geral, apresenta desnível para o palco sem equivalência em rampa ou equipamento eletromecânico.

- No que se refere à sinalização visual/tátil, o quadro evidencia um ponto crítico, com ausência em todos os edifícios. A única exceção corresponde ao prédio do ICA, que embora apresente sinalização, possui muitas incongruências, bem como espaços amplos, sem rota tátil ou outras referências para pessoas com deficiência visual (ver Figura 6). Espaços amplos e sem referências também foram observados no RU, Centro de Convivência e Biblioteca. Também destacam-se diversas situações de risco sem a devida sinalização tátil do tipo alerta.

- Na questão das circulações verticais, destacou-se como vermelho, pois, embora todos os edifícios visitados com mais de um pavimento possuam elevador ou plataforma, não se encontravam em funcionamento durante os percursos. $\mathrm{O}$ acesso aos pavimentos superiores é comprometido pela irregularidade em contratos de manutenção, ou pelo difícil manuseio.

Figura 5 - Rampa de acesso à Biblioteca. / Figura 6 - Estudante cego em área ampla e sem referências no ICA. / Figura 7 - Estudante em cadeira de rodas motorizada utilizando o balcão da área de atendimento da Biblioteca. / Figura 8 - Estudante em cadeira de rodas motorizada em frente ao acesso principal do auditório. / Figura 9 - Grelha de concreto junto às vagas reservadas do estacionamento. / Figura 10 - Estudante em cadeira de rodas manual próxima à bacia sanitária no sanitário acessível. / Figura 11 - Estudante em cadeira de

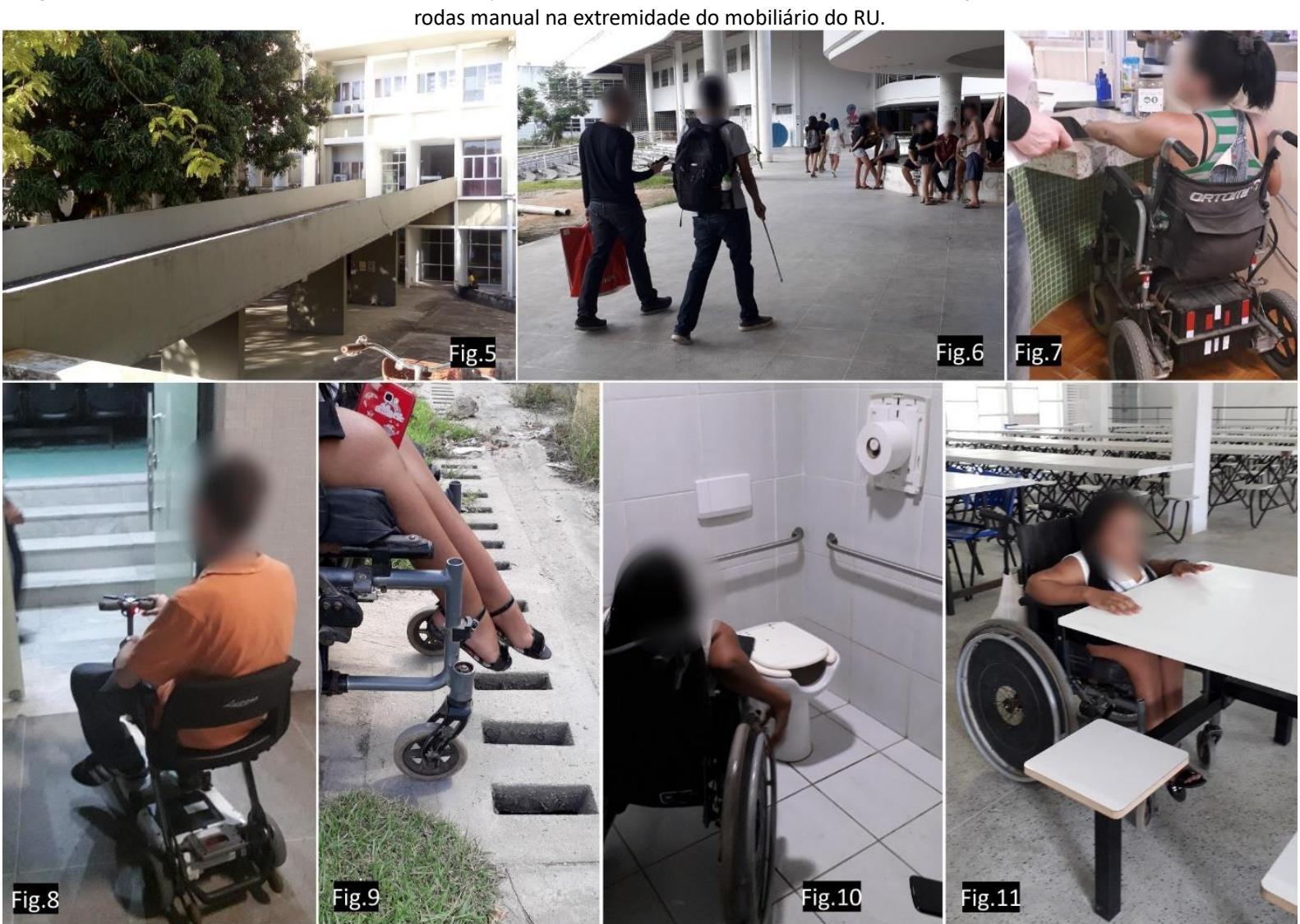

Fonte: Figuras 5: Acervo da pesquisa (2018), Figuras 6, 7, 8, 9, 10 e 11: Acervo da pesquisa (2019). 


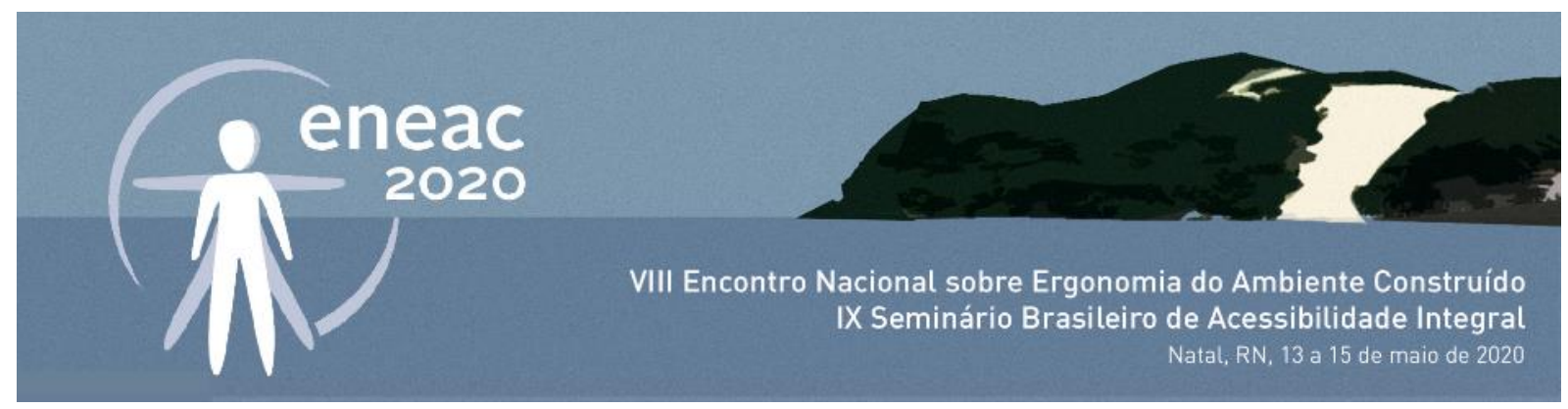

- No que se refere aos sanitários acessíveis, o quadro evidencia o atendimento parcial à normatização (ver Figura 10). A exceção seria o Auditório do CC, onde há total impossibilidade de uso dos sanitários por pessoas em cadeiras de rodas. Destaca-se ainda, nos sanitários acessíveis, a utilização de vasos com abertura frontal, que, com a experiência de utilização em banheiros públicos, constatou-se que podem dificultar o uso para pessoas com restrições de mobilidade nos membros inferiores e, por este motivo, vieram a ser proibidos pela NBR9050/2015.

- Quanto aos balcões, apenas na Biblioteca e no Centro de Convivência foram identificadas áreas rebaixadas com atendimento parcial aos parâmetros da NBR9050 (ver Figura 7). Nas demais edificações, marcadas como vermelho, os balcões não possuem rebaixo e são inacessíveis. Destaca-se o caso do RU, cujo balcão de autoatendimento das refeições não é acessível.

- Quanto aos bebedouros, não foram encontrados equipamentos que atendessem à normatização. O mobiliário também representa um ponto crítico, com destaque para o RU, cujo mobiliário com cadeiras fixas só permite aos estudantes em cadeira de rodas realizar as refeições nas extremidades (ver Figura 11). O mesmo ocorre nas mesas da cantina do Centro de Convivência. Destaca-se ainda a ausência de mesas para pessoas em cadeiras de rodas nas salas de aula do ICA e a ausência de espaços reservados e poltronas dimensionadas para pessoas obesas na plateia do Auditório do CC.

Num primeiro olhar, observa-se que muitas das intervenções de acessibilidade realizadas no Pici foram pensadas com objetivo de atender aos padrões mínimos das regulações. Um segundo olhar sobre estas adaptações mostra porém que, em muitos casos, estas atendem apenas parcialmente as regulações específicas, contendo muitas vezes os elementos necessários, porém em divergência com os parâmetros normativos/legais. Ou seja, mesmo os padrões mínimos são, não raro, descumpridos. Esta configuração de atendimento parcial acaba excluindo pessoas em condições mais restritivas de deficiência. Acrescenta-se que a atual configuração dos espaços universitários, seja pela falta total de acessibilidade ou atendimento parcial dos padrões mínimos, repercute diretamente na autonomia dos estudantes com deficiência, pois em muitos casos, só é possível utilizar ou acessar os ambientes de forma auxiliada, em desalinho com o conceito da inclusão.

Por fim, destaca-se que os espaços visitados no campus seguem a regra de muitos outros campi brasileiros: extrema racionalidade e padronização, negligência com os sentidos, com a convergência de fluxos, com os espaços de convivência. A estes fatores, somados aos muitos problemas de infraestrutura e acessibilidade dificultam a construção do campus como lugar de acolhimento de pessoas com deficiência, ou seja, desvirtuam o processo de "Moldagem do Lugar" (DUARTE, 1993). As diversas limitações e omissões impostas pelos espaços, bem como em outras dimensões da acessibilidade, implicam em aspectos emocionais negativos, influenciando diretamente na "acessibilidade psicológica" (ELALI, 2002), ou seja, os estudantes não se percebem como inseridos/inseríveis nos espaços universitários. Estas percepções mostram-se latentes pela repetição de algumas palavras-chave utilizadas em muitos discursos dos estudantes com deficiência quando da realização dos "passeios acompanhados": "medo", "trauma", "difícil”, "complicado", "risco". 


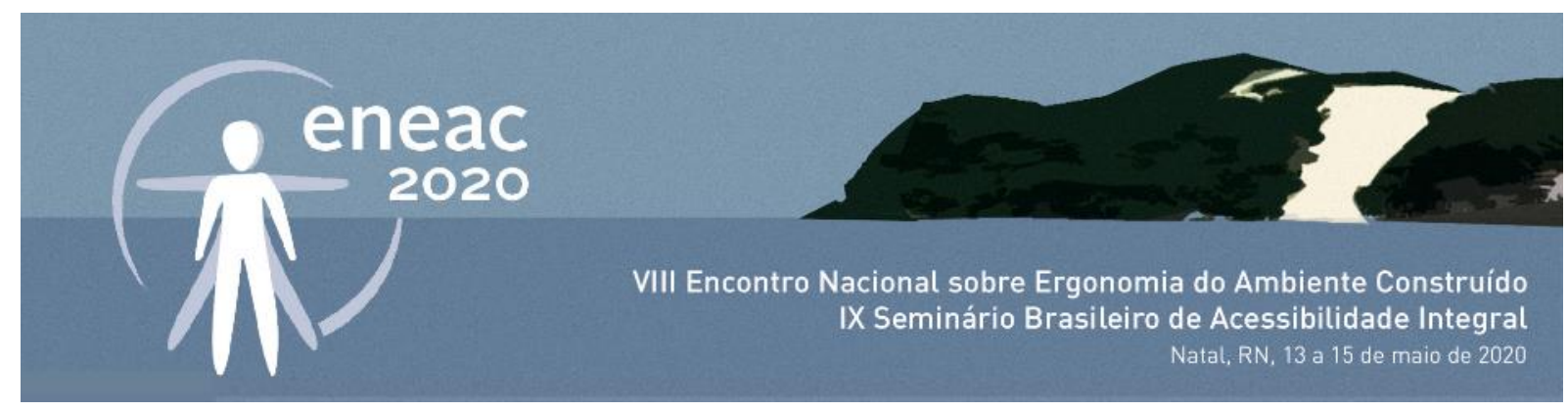

\section{CONSIDERAÇÕES FINAIS}

O campus universitário do Pici possui um grande potencial para possibilitar boas condições de acessibilidade e qualidade ambiental em geral, porém, os resultados apresentados nesta pesquisa mostram que ainda existem grandes lacunas quanto à acessibilidade espacial para o devido acolhimento dos estudantes com deficiência. As condições de acesso e uso dos espaços universitários no campus não são equitativas e a falta de uma cultura inclusiva desdobra-se na falta de interesse e força política para aprofundar as mudanças estruturais necessárias para a concretização de ambientes capazes de atender a todos.

Acreditamos que a Lei 13.409/2016, ao ampliar o número de pessoas com deficiência nas IFES, mediante as reservas de vagas, pode ser um veículo para a construção dessa cultura inclusiva dentro da Universidade e também para impulsionar novas transformações espaciais. Especula-se assim uma mudança de paradigma também quanto à acessibilidade espacial. Observa-se que a "inclusão espacial" (DUARTE, COHEN, 2004) na Universidade ocorre de forma lenta, porém progressiva. A concretização da acessibilidade espacial no campus do Pici e na Universidade Federal do Ceará como um todo, constituí um processo complexo de avanços e permanências, impulsionado por mudanças de legislações e normas, pressões internas e de órgãos de controle, e caracterizado por limitações orçamentárias. $\mathrm{O}$ desafio da Universidade no atual contexto é olhar para aquilo que foi feito e ladrilhar os caminhos remanescentes para chegarmos, enfim, à inclusão. No que tange ao espaço físico, alguns caminhos, diretrizes gerais foram pensadas como recomendações para construções ou reformas de campus acessíveis, elaboradas a partir da análise das informações coletas na pesquisa:

- Definir rotas acessíveis para interligação de todos os blocos e internamente a todos os ambientes. Esta premissa garante o acesso de todas as pessoas, inclusive pessoas com deficiência ou mobilidade reduzida aos espaços universitários.

- Priorizar rotas acessíveis estratégicas em: locais de maior circulação de pessoas, próximo a edificações de confluência (bibliotecas, restaurantes) e nos percursos entre os acessos do campus e os pontos de rotas de ônibus internos.

- As rotas entre blocos e as calçadas do campus devem ter superfície regular, firme, estável, não trepidante para dispositivos com rodas e antiderrapante, sob qualquer condição (seco ou molhado) e sinalizadas com rota visual/tátil para permitir a mobilidade de pessoas com deficiência visual. Priorizar o uso de referências edificadas, como jardineiras, guias de balizamento, evitando o uso demasiado de piso tátil direcional.

- Distanciar espécies arbustivas das rotas entre blocos e calçadas, pois frequentemente, devido à falta de manutenção, estas avançam sobre a faixa livre e dificultam ou impossibilitam o trânsito de pessoas.

- Na ocupação dos terrenos, priorizar a concentração e adensamento dos blocos, respeitando os devidos afastamentos e áreas de convivência e circulação. Construções dispersas e isoladas no campus privilegiam os deslocamentos por veículos e tendem a dificultar o acesso de pessoas com deficiência ou mobilidade reduzida. Ao reduzir as distâncias, o adensamento do espaço tende a torná-lo mais vivo, estimula o convívio e facilita os deslocamentos a pé. 


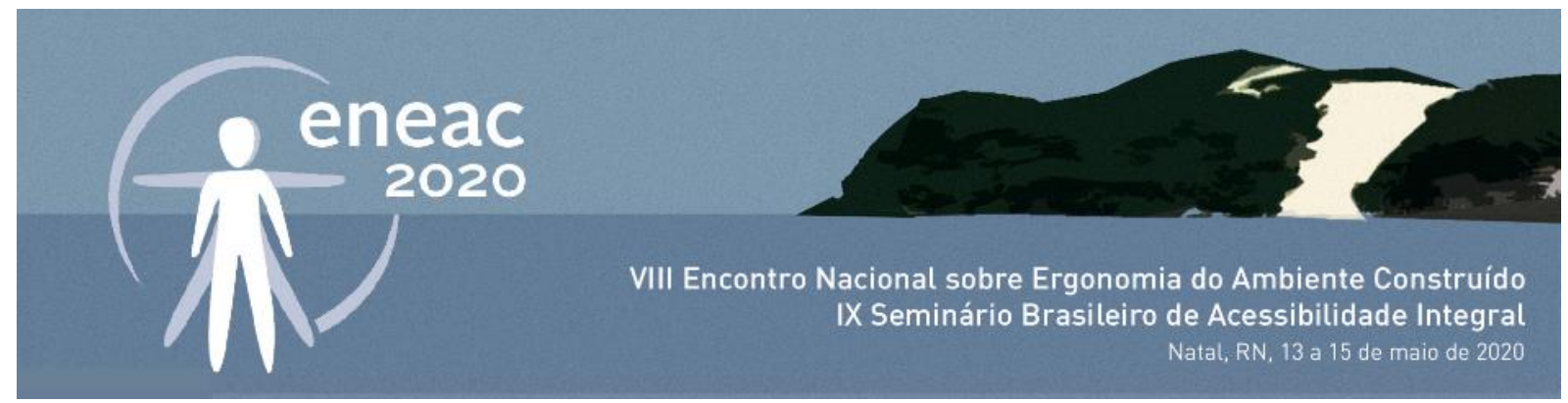

- Priorizar a construção de blocos diferenciados em aspetos formais ou cromáticos de forma a possibilitar melhor orientabilidade no campus.

- Concentrar os ambientes de maior aglomeração de estudantes (salas de aula, auditórios, laboratórios) nos pavimentos térreos a fim de evitar possíveis dificuldades de acesso aos pavimentos superiores, como plataformas e elevadores em manutenção.

- Priorizar, além de elevadores e plataformas, a construção de rampas para os pavimentos superiores a fim de evitar o impedimento de acesso devido às necessidades de reparo e inconstância em contratos de manutenção destes equipamentos.

- Concentrar os espaços de uso contínuo por pessoas com deficiência (plataformas e elevadores, rampas, vagas reservadas, sanitários acessíveis) próximos dos fluxos e aglomerações de pessoas (como espaços de convivência e portarias) para o caso de precisarem de auxílio.

- Instalar mapas táteis nos acessos do campus, bem como mapas táteis setoriais em pontos nodais de maior concentração de pessoas, como bibliotecas, auditórios, restaurantes.

- Fomentar a criação de tecnologias assistivas de uso pessoal para orientação e comunicação como forma de auxílio a pessoas com deficiência: códigos $Q R$, mapas virtuais, informações sobre rotas de ônibus, informações sobre rotas acessíveis, informações sobre localização de sanitários acessíveis, vagas reservadas, elementos de circulação vertical.

- Incluir pessoas com deficiência nos processos de projetação, principalmente no que diz respeito às adaptações de acessibilidade em espaços existentes.

\section{REFERÊNCIAS}

ASSOCIAÇÃO BRASILEIRA DE NORMAS TÉCNICAS. NBR 9050 - Acessibilidade a edificações, mobiliário, espaços e equipamentos urbanos. Rio de janeiro: ABNT, 2015.

. NBR 16537 - Acessibilidade - Sinalização tátil no piso - Diretrizes para elaboração de projetos e instalação. Rio de janeiro: ABNT, 2016.

ATCON, Rudolph P. Manual sobre o planejamento Integral do campus universitário. Florianópolis: Conselho de Reitores das Universidades Brasileiras, 1970.

Rumo à reformulação estrutural da universidade brasileira. Rio de Janeiro: MEC, 1966.

BRASIL. Ministério da Educação. Aviso Curricular n. 277, de 8 de maio de 1996. Brasília, DF, 1996a. Disponível em: <http://portal.mec.gov.br/seesp/arquivos/pdf/aviso277.pdf>. Acesso em: 2 abr. 2018.

Decreto № 5.296, de 2 de dezembro de 2004, que regulamenta as Leis nำ10.048, de 8 de novembro de 2000, e 10.098, de 19 de dezembro de 2000. Brasília, DF, 2004.

. Lei № 5.540 , de 28 de novembro de 1968. Fixa normas de organização e funcionamento do ensino superior e sua articulação com a escola média, e dá outras providências. Brasília, DF, 1968.

Lei 10.098, de 19 de dezembro de 2000, que estabelece normas gerais e critérios básicos para a promoção da acessibilidade das pessoas portadoras de deficiência ou com mobilidade reduzida, e dá outras providências. Brasília, DF, 2000.

. Lei № 12.711, de 29 de agosto de 2012. Dispõe sobre o ingresso nas universidades federais e nas instituições federais de ensino técnico de nível médio e dá outras providências. Brasília, DF, 2012.

. Lei Brasileira de Inclusão no 13.146, de 06 de julho de 2015. Brasília, DF, 2015.

. Lei № 13.409, de 28 de dezembro de 2016, que altera a Lei no 12.711, de 29 de agosto de 2012, para dispor sobre a reserva de vagas para pessoas com deficiência nos cursos técnico de nível médio e superior das instituições federais de 


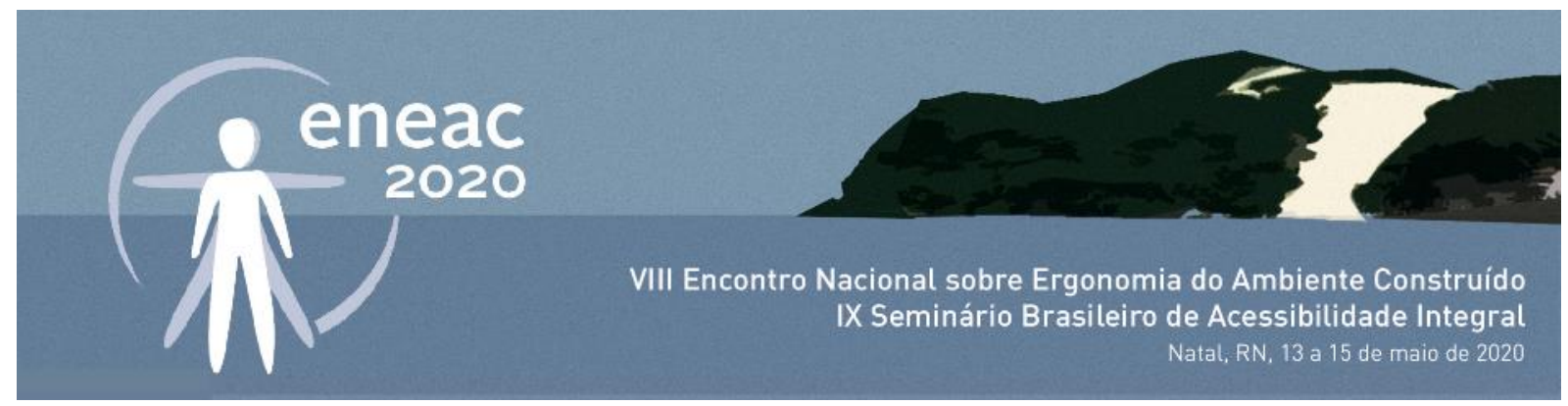

ensino. Brasília, DF, 2016.

Ministério da Educação. Portaria n.o 1.679 de 2 de dezembro de 1999. Dispõe sobre requisitos de acessibilidade de pessoas portadoras de deficiências, para instruir os processos de autorização e de reconhecimento de cursos, e de credenciamento de instituições. Brasília, DF, 1999.

Ministério da Educação. Portaria n. 3.284, de 7 de novembro de 2003. Dispõe sobre requisitos de acessibilidade de pessoas portadoras de deficiências, para instruir os processos de autorização e de reconhecimento de cursos e de credenciamento de instituições. 2003. Disponível em: <http://portal.mec.gov.br/seesp/arquivos/pdf/port3284.pdf>. Acesso em: 02 abr 2018.

CAMBIAGHI, Silvana. Desenho universal: métodos e técnicas para arquitetos e urbanistas. São Paulo: Editora Senac São Paulo, 2007.

DISCHINGER, Marta. Designing for all senses: accessible spaces for visually impaired citizens.Göteborg, Suécia, 2000. Department of Space and Process, School of Architecture, Chalmers University of Technology.

DUARTE, Cristiane Rose. Intervention Publique et Dynamique Sociale dans la Production d'un Nouvel Espace de Pauvrete Urbaine: Vila Pinheiros, a Rio de Janeiro - These de Doctorat de I'Universite Paris-I Panthéon Sorbonne, 1993.

DUARTE, Cristiane Rose; COHEN, Regina. Acessibilidade aos Espaços do Ensino e Pesquisa: Desenho Universal na UFRJ Possível ou Utópico? In: NUTAU 2004: Demandas Sociais, Inovações Tecnológicas e a Cidade, 2004, São Paulo. Anais NUTAU 2004: Demandas Sociais, Inovações Tecnológicas e a Cidade, 2004.

Acessibilidade e Desenho Universal: Fundamentação e revisão bibliográfica. Relatório técnico do Núcleo Pró-acesso, Rio de Janeiro, UFRJ, 2012.

ELALI, Gleice Azambuja. Um sistema para avaliação da acessibilidade em edificações do campus central da UFRN. In: SEMINÁRIO ACESSIBILIDADE NO COTIDIANO, 2002, Rio de Janeiro. Anais... Rio de Janeiro: PROARQ, 2002. Não paginado.

GIBSON, James J. The Ecological approach to Visual Perception. Hildalle, New Jersey: Lawrence Erlbaum, 1986.

INSTITUTO BRASILEIRO DE GEOGRAFIA E ESTATíSTICA. Censo Demográfico 2010. Características gerais da população, religião e pessoas com deficiência. Rio de Janeiro: Ministério do Planejamento, Orçamento e Gestão, IBGE, 2012, p. 1-215.

OLIVEIRA, Joaquim Aristides de. A universidade e seu território: um estudo sobre as concepções de campus e suas configurações no processo de formação do território da Universidade Federal do Ceará. Dissertação (Mestrado em Arquitetura e Urbanismo) - Faculdade de Arquitetura e Urbanismo da Universidade de São Paulo, São Paulo, 2005.

ORNSTEIN, Sheila; ROMÉRO, Marcelo. Avaliação Pós-Ocupação (APO) do ambiente construído. São Paulo: Studio Nobel: Editora da Universidade de São Paulo, 1992.

PINTO, Gelson de Almeida; BUFFA, Ester. Arquitetura e Educação: Câmpus Universitários Brasileiros. 1. ed. São Carlos: EdUFSCar, 2009. v. 1. 151p.

RHEINGANTZ, Paulo A., et al. Observando a Qualidade do Lugar: procedimentos para a avaliação pós-ocupação. Rio de Janeiro: Coleção PROARQ/FAU/UFRJ, 2009.

TUAN, Yi-fu. Espaço e lugar: a perspectiva da experiência. Tradução: Lívia de Oliveira. São Paulo: Difel, 1983. 250p. 